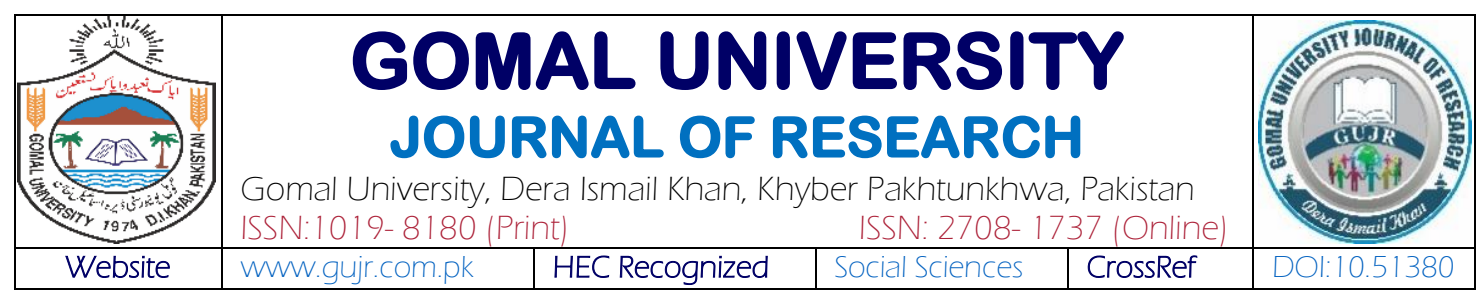

\title{
PSYCHOMETRIC VALIDATION OF ORGANIZATIONAL JUSTICE SCALE FOR SCHOOL TEACHERS IN PAKISTANI CONTEXT
}

\author{
Muhammad Aslam' \& Abid Hussain Chaudhary² \\ 'PhD Scholar, Institute of Education \& Research, University of Punjab, Pakistan \\ 2 Professor/Dean, Faculty of Education, University of Punjab, Lahore, Pakistan
}

\section{KEYWORDS \\ Organizational Justice, \\ Organizational Justice \\ scale, Psychometric \\ Validation, Reliability, \\ Validity \& Teachers}

\section{Article History}

Date of Submission:

20-09-2020

Date of Acceptance:

18-09-2021

Date of Publication:

30-09-2021

\section{ABSTRACT}

Organizational justice is about fairness at the workplace. It is essential to enhance performance and success of every organization. The study was conducted to validate Organizational Justice Scale (OJS) in Punjab, Pakistani public school context developed by Neihoff and Moorman (1993). Sample size consisted of 400 randomly selected public school teachers. This study was based upon quantitative approach and cross- sectional survey design was applied in data collection. The data was collected personally from teachers. Factors analysis techniques EFA and CFA were applied to confirm dimensionality, validity and reliability of Organizational Justice Scale (OJS) in schools of Pakistani context. Results are in support of three dimensional model (distributive, procedural \& interactional justice) and generalizability of this scale. Furthermore, the results also established adequate reliability and validity (convergent and discriminant validity) of OJS. Further studies can be conducted to further validate the OJS through different types of data analysis software and techniques. In addition, this scale would be useful for measurement of the organizational justice among teachers in schools.

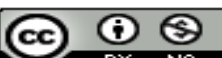

2021 Gomal University Journal of Research

Muhammad Aslam: aslamwatto@gmail.com

https://doi.org/10.51380/gujr-37-03-07

\section{INTRODUCTION}

The Organizational Justice (OJ) deals with individuals receiving against their contribution at workplace, procedures and allocation process during implementation of policies and decisions and way of interpersonal treatment at workplace. The employees' positive perceptions towards organizational justice lead to increase trust, well-being, satisfaction, emotional stability and performance of individuals as well as organizational success and performance (Colquitt, Scott, Rodell, Long, Zapata, Conlon, \& Wesson, 2013). Organizational justice refers as the individual interpretation of fairness in the organization. It provides an insight into how decisions are taken concerning the division of outcomes and the sense of justice over contribution (Sujono, Tunas, 
\& Sudiarditha, 2020). Adam's work of equity theory can be considered representative and the main advancement which emphases on matters of the fairness and justice at workplace. Thus, when we take Adam's equity theory as a reference, it described the perception of any worker regarding their input and outcome ration at the workplace and their comparison with other employees.

Equity theory proposed three major equity aspects that are named as underpayment, overpayment and fair payment when any employee compares his input/output ratio with other employees. The first aspect explained anger feelings of worker when he/she having lesser output to input ration while second aspect described the humiliation and guilt feelings of worker when he/she having more outcome to input ratio when compare with the other workers. The third aspect is equitable payment refers to the feelings of peace, honesty, bliss and contentment in workers (Gauri, 2013; Greenberg, 2010; Hamlett, 2014; McNabb, 2009; Oh, 2013; Zhang, 2006). The numbers of research studies on organizational justice that have been carried out in human resources management and organizational behaviour from the last three decades that show the relative impacts of this theory on the organizational variables. Furthermore, in study of OJ the dimensional aspect is still under debate. Consequently, literature on OJ increased the diversity of scales developed for measurement of the perceived organizational justice. There were two prominent OJS available: Neihoff and Moorman (1993) Organizational Justice Scale (OJS) with three dimensions (distributive, procedural, \& interactional) and the Colquitt's OJS (2001) with four dimensions (distributive, procedural, informational \& interpersonal) (Castaño \& García, 2018).

Although, Neihoff and Moorman (1993) OJS was frequently and widely utilized in the study of organizational justice (Gürbüz \& Mert, 2009). Salam (2020) confirmed three dimensional model of organizational justice scale (distributive, procedural \& interactional justice) and also confirm acceptable reliability and validity of scale. Exploratory Factor Analysis (EFA) and Confirmatory Factor Analysis (CFA) are two common techniques used in scale adaptation studies. In scale adaptation studies mostly researchers started with EFA and then applied CFA. EFA is applied to explore factors and structure of scale and CFA applied to confirm the factors and structure of scale (Orcan, 2018). The objectives of this study were to confirm dimensions and their related statements of Urdu version OJS. Furthermore, evaluate psychometric properties to ensuring reliability and validity of OJS over EFA and CFA for school teachers in Pakistani context. This study has a significant contribution in OJ literature. This study is significant for educational researchers and scholars to study OJ through validated OJS in current scenario. Specifically, to study that how OJ dimensions do impact on individuals, organizational performance and outcome variables.

\section{LITERATURE REVIEW}

Greenberg was first who recognized as founder of the term "organizational justice”. Here word, organization is considered as a workplace and word "justice" indicates fair dealings in matters occurred at workplace. These words literally described aspect of fair treatment and functioning at the workplace (Hamlett, 2014; Zhang, 2006). Theoretically, Greenberg introduced the term organizational justice in 1987 based on three forms of justice namely: distributive, procedural and interactional justice. Distributive justice is introduced by Adams in 1965, procedural justice is identified by Thibaut and Walker in 1975 and interactional justice is recognized by Bies and Moag in 1986 (Akram, Lei, Haider, \& Hussain, 2020; Hussain \& Khan, 2019). In this regard, 
the concept of Justice has been studied, developed and updated since 1950 in the organizational context. In this connection, the first wave 1950 to 1970 where scholars introduced distributive justice and stated that distribution of work and reward generates the fairness perceptions of workers.

Consequently, the first dimension of OJ was found (Hamlett, 2014; Zhang, 2006). The second phase from 1970 to 1990 where scholars moved their research direction distributive justice to procedural justice and indicated that procedures and decision making process for recourses allocation creates fairness perceptions of workers. Thus, another dimension of organizational justice as procedural justice was introduced (McNabb, 2009; Tam, 1998; Zhang, 2006). Then, in third phase scholars had introduced interactional justice as further dimension of organizational justice in 1980. Further, they indicated that treatment and communication manners and styles of management at workplace also contribute in perceived fairness of workers (Guo, 2009). The organizational justice is identified as ethical treatment, including justice in the distribution of results, procedural justice and interactional justice in workplace (Jameel, Mahmood, \& Jwmaa, 2020). The dimensionality aspect of the organizational justice is still under debate. Although, mostly studies rely on three dimensions of organizational justice initially proposed by Neihoff and Moorman (1993) and then further confirmed by Folger and Cropanzano (1998), namely: distributive, procedural and interactional justice. Similarly, Salam (2020) also confirmed the three dimensions of the organizational justice scale (distributive, procedural and interactional justice).

\section{Distributive Justice}

Distributive justice refers to the fair distribution of work at workplace and reward in form of salary, promotion and incentive provided to workers in organization (Gauri, 2013; Hamlett, 2014; McNabb, 2009; Oh, 2013). In this connection, McNabb (2009) stated that the term "distributive justice" was first introduced by Homans in 1961 in his exchange theory of social behavior. Further, he indicated that the distributive justice deals with individual perception of employee about reward provided to employees by the organization honestly, according to their contribution of work at workplace and equitably. Distributive justice refers to the perception of the fair and equitable organizational treatment and outcomes such as (pay, advantages, shift assignment, work assessments, promotions, and the workplace discipline). It is essential to recognize that equity and not equality are based on distributive justice. Equality implies that all employees are treated the same, regardless of their effort and contribution. Equity refers to the results determined by the particular individuals' efforts and contributions (Ahmad \& Jameel, 2021).

\section{Procedural Justice}

Oh (2013), Tam (1998) and Zhang (2006) indicated that Thibaut and Walker in 1975 introduced the term of procedural justice as a dimension of OJ and explained as the further perspective of distributive justice. Further, Guo (2009) and Wan, Sulaiman, and Omar (2012) described the procedural justice as the fairness in the decision making and procedure during distribution of resources, on the other hand distributive justice deals with the fair allocation of the work and remuneration. Procedural justice refers perceived fairness of the procedures used in making decisions. Procedural justice typically describes decision-making process used by an individual and is more closely connected to their assessment of a system. In this connection, if decisionmaking procedure is not open and fair then people will decrease their loyalty and satisfaction 
with the organization and increase their turnover (Jameel, Ahmad, \& Mousa, 2020; Salam, 2020).

\section{Interactional Justice}

Bies and Moag (1986) stated that the interactional justice as another dimension of the OJ and explained as the further perspective of procedural justice. Further, they described procedural justice as fair treatment and communication of management during implementation of policies and decisions. Also, Greenberg (1993) and Bies (1987) described procedural justice as perceived justice of individuals regarding treatment and interaction during decision making process and implementation of policies. Further, Bies (1987) discussed fair communication aspect during decision making and how much individuals treated honestly, respectfully and fairly. Interactional justice refers to fairness in interpersonal treatment of individuals. Interactional justice should consist of the justification of decision-makers ' decisions, as they influence people's perceptions of the fairness of their choices. A decision can be fair if adequate clarification was given, even if choice expected to produce adverse outcome (Jameel et al., 2020). Gürbüz and Mert, (2009) designed a research to evaluate validity and reliability of organizational justice scale developed by Neihoff and Moorman (1993) in Turkish context and confirmed the three factors model of OJS.

Moreover, they also confirmed the acceptable reliability and validity of OJS in Turkish context. Furthermore, Castaño Pérez and García-Izquierdo (2018) conducted a study to validate the Organizational Justice Scale (OJS) in Spainish context. This study provided further evidence for good psychometric properties of the OJS. The validation of OJS was conducted by means of an exploratory and confirmatory factor analysis. They found three factor model: distributive, procedural, and interactional of OJS with acceptable reliability and validity. They argued that OJS is an appropriate tool for use by researchers and practitioners in the study of perceived organizational justice in Spain. In the educational institutions in Pakistan, maximum research studies utilized OJS without contextual validation. Consequently, there is need to ensure the dimensions, reliability and validity of the OJS for utilization in the educational organizations for measurement of organizational justice. Therefore, this study was an attempt to validate this scale in the Pakistani cultural context with the participants from the school level educational organizations.

\section{Purpose of Study}

The primary purpose of this study was to authenticate the dimensions, reliability and validity of organizational justice scale developed by Neihoff and Moorman (1993) through EFA and CFA for the school level teachers in Pakistani context. In addition, this scale would be useful for measurement of organizational justice among teachers in schools in developing countries like Pakistan.

\section{Research Objective}

To validate the organizational justice scale in Pakistani context school teachers through EFA and CFA.

\section{Research Questions}

How many dimensions are vital for the measurement model regarding the organizational justice scale?

What are values of reliability and validity of organizational justice scale in schools of Pakistani context? 


\section{RESEARCH METHODOLOGY}

This research was conducted to ensure dimensionality, validity and reliability of Organizational Justice Scale (OJS) developed by Neihoff and Moorman (1993) in context of public-schools in Punjab, Pakistan. In order to validate OJS, a survey was conducted among teachers of public schools in Punjab Pakistan. This study was based on quantitative research and cross-sectional survey design was applied in the data collection. Neihoff and Moorman (1993) Organizational Justice Scale (OJS) was utilized for data. Scale included twenty statements with six-point level Likert scale from strongly disagree (1) to strongly agree (6). This scale was comprised of three dimensions namely: distributive (5- statements), procedural (6- statements), and interactional justice (9- statements). The reliability of all dimensions in original scale was above 0.90. This scale was considered a reliable instrument in conducting organizational justice research. OJS was translated into Urdu to unearth more accurate data regarding OJ from teachers of public schools.

Likewise, Orcan (2018) mentioned step by step process for translating scale into another language. Accordingly, at first step, two language experts translated the OJS into Urdu. Secondly, one different language expert finalized the translation. At third step, translated scale was translated back into English by two new experts. Lastly, these translations were evaluated and finalized by one more new translation expert. Data was collected from 400 randomly selected teachers of District Okara. Data were collected by researchers. Data was analysed by applying SPSS, AMOS. EFA and CFA were applied to ensure dimensionality, validity and reliability of OJS in Pakistani context.

\section{DATA ANALYSIS}

The data was analysed by using SPSS 22.0 AMOS. EFA and CFA were applied to evaluate the psychometric properties of the organizational justice scale developed by Neihoff and Moorman (1993) in Pakistani context school teachers.

\section{EFA on Organizational Justice Scale}

EFA was performed to authenticate the factors and their respective statements for instrument of organizational Justice.

\section{Table 1}

KMO and Bartlett's Test of OJS

\begin{tabular}{lll}
\hline KMO and Bartlett's Test & & \\
\hline KMO Measure of Sampling Adequacy. & & .938 \\
Bartlett's Test of Sphericity (BTS) & Approx. Chi-Square & 4425.195 \\
& Df & 190 \\
\hline & Sig. & .000 \\
\hline
\end{tabular}

The data is considered fit for factor analysis if the value of KMO is greater than 0.6 and the value of BTS is significant (i.e. the significant value should be 0.05 or smaller). The value of $\mathrm{KMO}$ for the instrument of organizational justice is 0.938 and BTS is significant. It shows that the data obtained through organizational justice instrument is suitable to run the factor analysis. 
Table 2

Items' Correlations of Organizational Justice Scale

\begin{tabular}{lcc}
\hline & Communalities & \\
\hline OJ1 & Initial & Extraction \\
OJ2 & 1.00 & .713 \\
OJ3 & 1.00 & .734 \\
OJ4 & 1.00 & .862 \\
OJ5 & 1.00 & .810 \\
OJ6 & 1.00 & .820 \\
OJ7 & 1.00 & .712 \\
OJ8 & 1.00 & .872 \\
OJ9 & 1.00 & .880 \\
OJ10 & 1.00 & .704 \\
OJ11 & 1.00 & .820 \\
OJ12 & 1.00 & .772 \\
OJ13 & 1.00 & .746 \\
OJ14 & 1.00 & .754 \\
OJ15 & 1.00 & .801 \\
0J16 & 1.00 & .854 \\
OJ17 & 1.00 & .823 \\
OJ18 & 1.00 & .779 \\
OJ19 & 1.00 & .795 \\
OJ20 & 1.00 & .778 \\
\hline
\end{tabular}

Extraction Method: Principal Component Analysis (PCA).

Notes: OJ = Organizational justice

The table of communalities demonstrates the values of correlation. All the items extracted from exploratory factor analysis have correlation 0.50 or greater 0.5 . This shows that all the statements are suitable to proceed the factor analysis.

\section{Table 3}

Factors Loadings using Eigenvalues Criteria

\begin{tabular}{|c|c|c|c|c|c|c|c|c|c|}
\hline \multirow{3}{*}{ COMP } & \multicolumn{9}{|c|}{ Total Variance Explained } \\
\hline & \multicolumn{3}{|c|}{ Initial Eigenvalues } & \multicolumn{3}{|c|}{$\begin{array}{c}\text { Extraction Sums of Squared } \\
\text { Loadings }\end{array}$} & \multicolumn{3}{|c|}{$\begin{array}{c}\text { Rotation Sums of Squared } \\
\text { Loadings }\end{array}$} \\
\hline & Total & $\begin{array}{c}\% \text { of } \\
\text { Variance }\end{array}$ & $\begin{array}{l}\text { Cumulative } \\
\%\end{array}$ & Total & $\begin{array}{c}\% \text { of } \\
\text { Variance }\end{array}$ & $\begin{array}{c}\text { Cumulative } \\
\%\end{array}$ & Total & $\begin{array}{c}\% \text { of } \\
\text { Variance }\end{array}$ & Cumulative \% \\
\hline 1 & 9.241 & 46.205 & 46.205 & 9.241 & 46.205 & 46.205 & 4.691 & 23.453 & 23.453 \\
\hline 2 & 1.558 & 7.790 & 53.995 & 1.558 & 7.790 & 53.995 & 4.313 & 21.564 & 45.016 \\
\hline 3 & 1.044 & 5.221 & 59.216 & 1.044 & 5.221 & 59.216 & 2.840 & 14.200 & 59.216 \\
\hline 4 & .972 & 4.860 & 64.077 & & & & & & \\
\hline 5 & .785 & 3.927 & 68.003 & & & & & & \\
\hline 6 & .660 & 3.302 & 71.305 & & & & & & \\
\hline 7 & 641 & 3.206 & 74.511 & & & & & & \\
\hline 8 & .632 & 3.159 & 77.671 & & & & & & \\
\hline 9 & .560 & 2.802 & 80.472 & & & & & & \\
\hline
\end{tabular}




\begin{tabular}{cccc}
10 & .506 & 2.528 & 83.000 \\
11 & .478 & 2.390 & 85.391 \\
12 & .469 & 2.344 & 87.734 \\
13 & .421 & 2.107 & 89.841 \\
14 & .371 & 1.855 & 91.696 \\
15 & .343 & 1.714 & 93.410 \\
16 & .328 & 1.640 & 95.051 \\
17 & .293 & 1.463 & 96.513 \\
18 & .257 & 1.283 & 97.797 \\
19 & .245 & 1.226 & 99.023 \\
20 & .195 & .977 & 100.000 \\
\hline
\end{tabular}

Extraction Method: PCA.

Those components are considered suitable for instrument which has Eigen values more than 1 using Kaiser's criterion. In the table above, it can be observed that three factors are extracted which have Eigen values more than 1. These three factors have Eigen values $(9.241,1.558$ and 1.044) respectively. The variance explicated by these three dimensions is $59.216 \%$ of total variance.

\section{Figure 1}

Scree Plot of Factors of Organizational Justice Scale

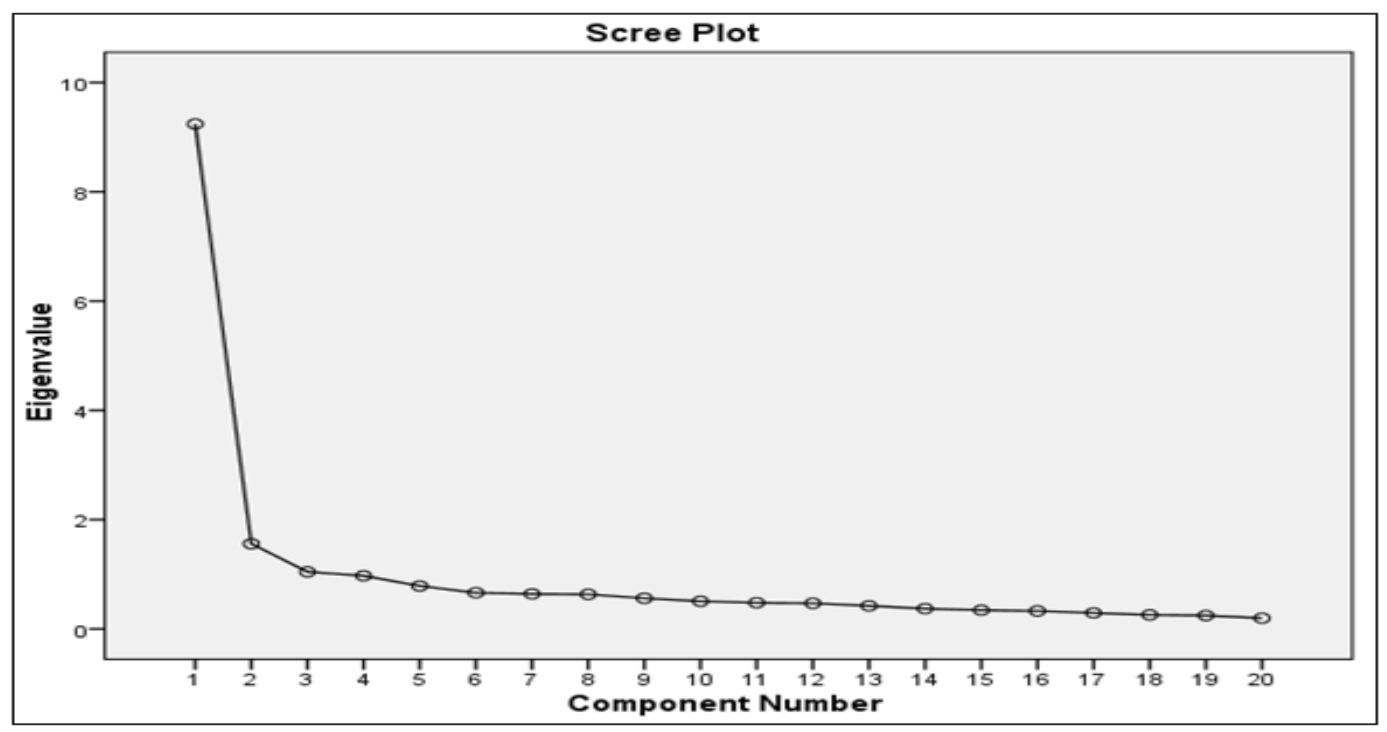

In factor analysis, the scree plots are often checked while using the Kaiser's criterion. Those components are retained before the change (elbow) in the form of the plot. In above case, there is an apparent break down between 1st and 2nd components. Component 1 captures most of the variance than the remaining components 2nd and $3 \mathrm{rd}$. There is also a small break down after the 3rd component. Therefore, three components are extracted based on Scree plot (see figure 1). 
Table 4

Exploratory Factor Analysis of Organizational Justice Scale using Principal Component

\begin{tabular}{lccc}
\hline \multicolumn{3}{c}{ Component Matrixa } \\
\hline & 1 & Component \\
OJ15 & .802 & 2 & 3 \\
OJ16 & .787 & & .789 \\
OJ9 & .774 & & .308 \\
OJ18 & .769 & .305 \\
OJ17 & .753 & & .306 \\
OJ7 & .747 & & .719 \\
OJ20 & .747 & & .382 \\
OJ13 & .744 & & .747 \\
OJ8 & .743 & & .790 \\
OJ19 & .716 & .742 \\
OJ12 & .711 & .810 \\
OJ6 & .706 & .741 & \\
OJ14 & .793 & .709 & \\
OJ11 & .760 & .757 & \\
OJ10 & .730 & .740 & \\
OJ4 & .639 & .701 & \\
OJ5 & .629 & & \\
OJ3 & .602 & & \\
OJ2 & .687 & & \\
OJ1 & .644 & & \\
Extraction Method: PCA. & & & \\
\hline a. 3 components extracted. & & & \\
\hline
\end{tabular}

Using Kaiser's criterion, it can be observed in the component matrix table, three factors are extracted. In the component matrix table, it can be observed that items are loaded on three components respectively. Hence, it can be concluded that the three factors solution is more appropriate.

Table 5

Exploratory Factor Analysis of Organizational Justice Scale using Pattern Matrix

\begin{tabular}{|c|c|c|c|}
\hline \multicolumn{4}{|c|}{ Rotated Component Matrixa } \\
\hline & & npo & \\
\hline & 1 & 2 & 3 \\
\hline OI19 & .780 & & \\
\hline 0J18 & .752 & & \\
\hline 0J17 & .749 & & \\
\hline OJ20 & .749 & & \\
\hline $0 J 7$ & .783 & & \\
\hline $0 J 6$ & .757 & & \\
\hline $0 \mathrm{~J} 8$ & .743 & & \\
\hline
\end{tabular}


\begin{tabular}{lll} 
OJ16 & .730 & \\
OJ13 & .814 & \\
OJ12 & .736 & \\
OJ11 & .701 & \\
OJ10 & .739 & .713 \\
OJ15 & .784 & .769 \\
OJ14 & .745 & .754 \\
OJ9 & .727 & .753 \\
OJ3 & & .717 \\
OJ5 & & .73 \\
OJ2 & & \\
OJ1 & & \\
OJ4 & & \\
\hline
\end{tabular}

Extraction Method: PCA. Rotation Method: Varimax with Kaiser Normalization.

a. Rotation converged in six iterations.

Note: Component 1=Interactional Justice (IJ), 2=Procedural Justice (PJ), 3=Distributive Justice (DJ)

Rotated component matrix is considered an essential component before making final decision about the extraction of factors. Varimax Rotation technique was applied to extract the factors because negative items were in large numbers when Direct Oblimin method was used to extract the items and their respective factors. In above table, it can be seen that items are being loaded on three components. On first and second component, 8 and 7 items were loaded respectively. Five items were loaded on distributive justice. Initially, items, 6,7 and 8 were part of procedural justice but these were loaded in interactional justice after EFA. Likewise, items 12, 13, 14 and 15 were part of interactional justice but these items were uploaded in procedural justice after the EFA.

\section{CFA on Organizational Justice Scale}

CFA was applied to confirm best fit model identified in EFA. Preliminary analysis confirmed that the data was normally distributed and data was fit for the application of CFA. The output of confirmatory factor analysis $\left(\chi_{2} / \mathrm{CMIN} / \mathrm{DF}=3.671, \mathrm{GFI}=0.866, \mathrm{AGFI}=0.831, \mathrm{TLI}=0.891, \mathrm{CFI}\right.$ $=0.897$, RMSEA $=0.082$ ) confirmed structure of questionnaire CFA confirmed three factors for model.

$\mathrm{Hu}$ and Bentler (1999) gave the threshold to evaluate the model fit for CFA. According to them, Chi-Square, CMIN/DF value of $\leq 3$ is considered good whereas value $<5$ is sometime permissible for model fit. In the present study, the value of CMIN/DF is 3.671 which is below the threshold value given by $\mathrm{Hu}$ and Bentler (1999). Furthermore, the value of CFI above and close to 0.90 is acceptable and good fit for model. The value obtained for CFI in this study is 0.897 which is in between the threshold values given by Hu and Bentler (1999). The value of TLI (Tucker Lewis Index) is considered good if it is greater than 0.95. The value of TLI in the current study is 0.891 which indicates a good fit for the current model. The value of AGFI is greater than 0.80 considered good. The value of AGFI in this study is 0.831 which satisfy this assumption. The value of RMSEA is considered good, moderate and bad if it is <0.05, 0.05-0.10 and $>0.10$. In this study, the value of the RMSEA is 0.082 which is considered moderate and validate this assumption. 


\section{Validity of Organizational Justice Scale}

Convergent validity is measured using three different methods. First and prime, if standardized loadings of items are statistically significant and standardized estimate value is 0.50 or higher, then the factor is said to achieve convergent validity. In table 2, all the items in organizational justice scale loaded above 0.50, the cut off score. It can be concluded that items of OJS achieved convergent validity. Secondly, convergent validity is assessed from values of Average Variance Extracted (AVE). AVE can be calculated using the factor loadings. The formula of AVE is given below.

$\mathrm{AVE}=\mathrm{n} \Sigma \mathrm{i}=\mathrm{o}$ Li2 $/ \mathrm{n}$

The Li represents the standardized loadings and " $\mathrm{i}$ " represents the number of items. An AVE of 0.50 or higher is considered adequate for convergent validity. The values of AVE for constructs of organizational justice are given in table 6 . Furthermore, convergent validity is measured in terms of composite reliability and Cronbach's alpha. The values of CR and Cronbach's alpha ( $\boldsymbol{\alpha})$ were greater than 0.70 considered adequate to measure convergent validity of the instrument. The values of CR and $\boldsymbol{\alpha}$ for the constructs of organizational justice instrument are given in table 6.

\section{Table 6}

Convergent Validity of Factors of Organizational Justice Scale

\begin{tabular}{cccc}
\hline Name of constructs & Values of AVE & $\begin{array}{l}\text { Values of Cronbach's } \\
\text { Alpha }(\boldsymbol{\alpha})\end{array}$ & $\begin{array}{l}\text { Values of Composite } \\
\text { Reliability (CR) }\end{array}$ \\
\hline DJ & 0.741 & 0.843 & 0.859 \\
PJ & 0.866 & 0.894 & 0.900 \\
\hline IJ & 0.869 & 0.909 & 0.914 \\
\hline
\end{tabular}

The values of AVE is considered good if it is greater than 0.50. The AVE value of all factors of organizational justice is greater than 0.50 which established the first assumption of convergent validity. In this regard, the values of $\mathrm{CR}$ and $\boldsymbol{\alpha}$ of the all factors of organizational justice are greater than 0.70 which also indicates that convergent validity is established between items and their respective factors. In this connection, the Instrument is said to have good discriminant validity if one construct of that instrument is not highly correlated to the other constructs of that instrument. The value of discriminant validity greater than 0.85 between two constructs is considered statistically overlap, it is said that both the constructs are measuring the same thing. The values of discriminant validity for the instrument of organizational justice are given in table 7 .

Table 7

Discriminant Validity of Factors of Organizational Justice Scale

\begin{tabular}{cccc}
\hline Name of Constructs & 1 & 2 & 3 \\
\hline IJ & 0.869 & & \\
PJ & 0.834 & 0.866 & 0.861 \\
\hline DJ & 0.649 & 0.665 & \\
\hline
\end{tabular}

The table 7 shows discriminant validity of factors of organizational justice scale. The discriminant validity values of factors for instrument of organizational justice are less than 0.85 . Correlation 
between procedural and interactional justice is 0.834 which establishes the assumption of the discriminant validity $(\leq 0.85)$. in this connection, hence, it can be concluded from the results that the discriminant validity is thus also established between the factors of the organizational justice.

\section{DISCUSSION}

It presents that this study was conducted to validate the Organizational Justice Scale developed by Neihoff and Moorman (1993) in Pakistani context. Initially, the statements OJ6, OJ7 and OJ8 were the part of procedural justice but these were loaded in interactional justice after the EFA. Likewise, statements OJ12, OJ13, OJ14 and OJ15 were the part of interactional justice but these items were loaded in procedural justice after the EFA. In component matrix table, it can be found that the statements are loaded on three components respectively. Therefore, it can be concluded that three factors solution is more appropriate. The CFA was applied to confirm the best fit model identified in exploratory factor analysis. Preliminary analysis confirmed that the data was normally distributed and data was fit for application of confirmatory factor analysis. The results of CFA confirmed the structure of the scale. The CFA confirmed the three factors for model. These findings are similar with study of Neihoff and Moorman (1993) that organizational justice scale consisted of three factors namely: the distributive, procedural and interactional justice.

Moreover, Cohen-Charash and Spector's (2001), Gürbüz and Mert, (2009), and Ozmen, Arbak, and Ozer (2007) were also confirmed three factors model of Organizational Justice Scale (OJS). Therefore, the three dimensional model of organizational justice scale (distributive, procedural and interactional justice) is appropriate. Moreover, Castaño Pérez and García-Izquierdo (2018) also confirmed the three factors model of OJS with acceptable reliability and validity. All the statements in the organizational justice scale were loaded above 0.50 , the cut off score. It was concluded that all statements of organizational justice scale achieved the convergent validity. Furthermore, convergent validity was also assessed from the values of AVE. The values of AVE for the factors of organizational justice scale were greater than 0.50 which also established the assumption of the convergent validity. The values of CR and $\boldsymbol{\alpha}$ for constructs of organizational justice scale were greater than 0.70 which indicates that convergent validity was established between items and their respective constructs. These findings of this study are similar with the study of Gürbüz and Mert (2009), in which they confirm reliability and validity of organizational justice scale.

Similarly, Salam (2020) also investigated that Composite Reliability (CR) and Cronbach's Alpha of all constructs of organizational justice were above the suggested level 0.70 , which indicate to high internal consistency of the scale. Likewise, AVE values of all dimensions of organizational justice exceed 0.5 which established the assumption of convergent validity of scale. Moreover, the values of discriminant validity of constructs for organizational justice scale were less than 0.85 which established assumption of discriminant validity $(\leq 0.85)$. Hence, it was concluded that discriminant validity is also established between the constructs of OJS. Similarly, Salam (2020) also confirmed the discriminate validity of the constructs of organizational justice. He indicated that each construct was correlated with itself higher than others constructs. In this connection, on the whole, the results of the present study justified regarding OJS for school teachers in Pakistani context as the teachers of the Pakistani context are supposed to work in a 
setting where the organizational structure was established according to international scenario and structure.

\section{CONCLUSION}

The goal of present study was to evaluate the psychometric properties in order to validate the Urdu version OJS for teachers of Pakistani context. It can be concluded on the basis of results that three factors model solution is appropriate for OJS (distributive, procedural \& interactional justice). Initially, the data analysis confirmed that the data was normally distributed and fit for the application of factor analysis. The results of factor analysis confirmed three factors solution for the model of OJS included distributive, procedural and interactional justice. Further, it can be concluded that results of this study confirmed acceptable reliability (Composite Reliability (CR) and Cronbach's Alpha) and validity (convergent and discriminate validity) assumptions of organizational justice scale. Therefore, it can be concluded that Urdu version of OJS developed by Neihoff and Moorman (1993) is valid and reliable scale for Pakistani context schools. In addition, this scale would be useful for measurement of organizational justice among teachers in schools.

\section{Limitations \& Recommendations}

This study was conducted to ensure dimensionality, validity and reliability of the organizational justice scale developed by Neihoff and Moorman (1993) in Punjab, Pakistani public schools context. The participants for this study were only teachers selected from school level educational institutions. For increased generalizability of findings, future studies need to examine whether same results could be found from the larger sample from the same organizations and different organizations context. Although there is need of studies in different context to further validate this scale for measurement of organizational justice over diverse types of data analysis software and techniques.

\section{REFERENCES}

Ahmad, A., \& Jameel, A. S. (2021). Effect of organizational justice dimensions on performance of academic staff in developing countries. Annals of the Romanian Society for Cell Biology, 25(3), 259-270.

Akram, T., Lei, S., Haider, M. J., \& Hussain, S. T. (2020). The impact of organizational justice on employee innovative work behavior: Mediating role of knowledge sharing. Journal of Innovation \& Knowledge, 5(2), 117-129.

Bies, R. J. (1987). The predicament of injustice: The management of moral outrage. In L. Cummings, \& B. Staw (Eds.), Research in organizational behavior (289-319). Greenwich, CT: JAI Press.

Bies, R. J., \& Moag, J. F. (1986). Interactional justice: Communication criteria of fairness. In R. J. Lewicki, H. Sheppard \& H. Bazerman (Eds.), Research on negotiation in organizations (pp. 43-55). Greenwich: CT: JAI Press.

Castaño Pérez, A. M., \& García-Izquierdo, A. L. (2018). Validity evidence of the organizational justice scale in Spain. Psicothema, 30(3), 344-350.

Cohen-Charash, Y., \& Spector, P. E. (2001). The role of justice in organizations: A metaanalysis. Organizational behavior and human decision processes, 86(2), 278-321. 
Colquitt, J., Scott, B., Rodell, J., Long, D., Zapata, C., Conlon, D., \& Wesson, M. (2013). Justice at the millennium, a decade later: A metaanalytic test of social exchange and affect-based perspectives. Journal of Applied Psychology, 98(2), 199-236.

Folger, R., \& Cropanzano, R. (1998). Organizational justice and human resource. Thousand Oaks, CA: Sage.

Greenberg, J. (1993). The social side of fairness: Interpersonal and informational classes of organizational justice in the workplace. In C. Russell (Ed.), Justice in workplace: Approaching fairness in human resources management (pp. 79-103). Hillsdale, NJ: Lawrence Eribaum Associates.

Guo, C. (2009). The meaning and effects of organizational justice in a layoff situation: An indigenous chinese investigation (Doctoral dissertation, University of Massachusetts Amherst). Retrieved from https://scholarworks.umass.edu/dissertations 1/123.

Gürbüz, S., \& Mert, I. S. (2009). Validity and reliability testing of organizational justice scale: An empirical study in a public organization. Review of Public Administration, 42(3), 117-139.

Hamlett, J. (2014). Exploring how Managers' Perception of Organizational Justice Influences Job Satisfaction and Turnover Intention. (Doctoral dissertation, Northcentral University).

Hu, L. T., \& Bentler, P. M. (1999). Cutoff criteria for fit indexes in covariance structure analysis: Conventional criteria versus new alternatives. Structural equation modeling: $A$ Multidisciplinary Journal, 6(1), 1-55.

Hussain, M., \& Khan, M. S. (2019). Organizational justice and turnover intentions: probing the Pakistani print media sector. In Evidence-based HRM: a Global Forum for Empirical Scholarship. Emerald Publishing Limited.

Jameel, A. S., Ahmad, A. R., \& Mousa, T. S. (2020). Organizational justice and job performance of academic staff at public universities in Iraq. Skyline Business Journal, 16(1), 13-29.

Jameel, A. S., Hamdi, S. S., Abdul-Karem, M., \& Ahmad, A. R. (2020). Organizational Justice and Job satisfaction among nurses. UKH Journal of Social Sciences, 4(2), 61-69.

Jameel, A. S., Mahmood, N., \& Jwmaa, S. J. (2020). Organizational justice and organizational commitment among secondary school teachers. Journal of Humanities and Social Sciences, 4(1), 1-6.

McNabb, N. S. (2009). The daily floggings will continue until morale improves: An examination of the relationships among organizational justice, job satisfaction, organizational commitment and intention to turnover (Doctoral dissertation, University of Oklahoma, Graduate College).

Niehoff, B., \& Moorman, R. (1993). Justice as mediator of the relationship between methods of monitoring and organizational citizenship behaviour. Academy of Management Journal, 36(3), 527-556.

Oh, J. R. (2013). The impact of organizational justice on career satisfaction of employees in the public sector of South Korea (Doctoral dissertation, University of Minnesota). Retrieved from http://hdl.handle.net/11299/154067.

Orcan, F. (2018). Exploratory and confirmatory factor analysis: which one to use first. Journal of Measurement and Evaluation in Education and Psychology, 9(4), 414-421.

Ozmen, O. N., Arbak, Y., \& Ozer, P. S. (2007). Adalete verilen degerin adalet algilari uzerindeki etkisinin sorgulanmasina iliskin bir arastirma. Ege Academic Review, 7(1), 19-35.

Pallant, J. (2016). SPSS Survival manual: A step by step guide to data analysis using SPSS program. London: McGraw-Hill Education. 


\section{Aslam \& Chaudhary ... Psychometric Validation Of}

Salam, A. (2020). Organizational justice as a predictor of organizational citizenship behaviour. International Business Education Journal, 13, 29-42.

Sujono, D., Tunas, B., \& R Sudiarditha, I. K. (2020). Vitality of work involvement in mediation: The effect of organizational justice on organizational citizenship behavior. Management Science Letters, 10(5), 1061-1068.

Tam, W. W. (1999). An assessment of the relationships among organizational trust, organizational politics, and organizational justice, and their effects on merit pay outcomes in the Malaysian public sector (Doctoral dissertation, The Pennsylvania State University).

Wan, H., Sulaiman, M., \& Omar, A. (2012). Procedural justice in promotion decisions of managerial staff in Malaysia. Asia Pacific Business Review, 18(1), 99-121.

Zhang, H. (2006). Antecedents and consequences of organizational justice: An investigation in China (Doctoral dissertation, McMaster University). Retrieved from http://hdl. handle.net/11375/20098. 